\title{
OPTIMASI PERSEDIAAN MATERIAL TRANSFORMATOR MENGGUNAKAN METODE JARINGAN SYARAF TIRUAN DAN ANT COLONY OPTIMIZATION DI PT. PLN (PERSERO) AREA JEMBER
}

\author{
Rizki Herdatullah*, Syaiful Bukhori**, Windi Eka Yulia Retnani*** \\ $*, * *, * * *$ Sistem Informasi, Fakultas Ilmu Komputer, Universitas Jember (UNEJ) \\ *e-mail@address,**e-mail@address,***e-mail@address
}

\begin{abstract}
Optimization comes from basic words optimal which mean the best, highest, most beneficial, make the best, and do optimizing (make the best, highest, etc.). Forecasting is an attempt to predict the future. Prediction can be done by studying the pattern of historical data to find a model that can show future data. This methoed is called time series data forecasting. One of many algorithm that can builds model from historical data is Artificial Neural Networks (ANN). The algoritm mimics the human neuron system so that is can solve non-linear problems, such as the forecasting of transformator demand.

In the process of modeling, ANN will always update the connection weights to find the optimum weights. In this final project ANN will be trained by Ant Colony Optimization (ACO). Based on the results can be seen that ANN with ACO as learning methods can predict transformator demand with good result.
\end{abstract}

Keyword: Artificial Neural Networt, Ant Colony Optimization

\section{Introduction}

Setiap perusahaan memiliki tantangan untuk memperkirakan jumlah barang yang harus di produksi untuk memenuhi permintaan pasar yang terus berubah seiring waktu. Semakin baik perusahaan menangani tantangan ini, maka akan berdampak besar pada profitabilitas. Kelebihan jumlah pasokan akan berpengaruh pada ketersediaan tempat penyimpanan dan juga berpengaruh terhadap kualitas barang yang disimpan. Sebaliknya, apabila jumlah pasokan kurang dari pemintaan pasar maka perusahaan akan kehilangan kesempatan untuk mendapatkan keuntungan yang lebih besar.

Munculnya kondisi ketidakpastian dalam perusahaan untuk memenuhi permintaan pasar mendorong perusahaan untuk melakukan efisiensi dan optimasi dalam menjalankan proses bisnisnya. Efisiensi dan optimasi ini dapat dicapai dengan menerapkan manajemen terhadap persediaan secara tepat.

PT PLN (Persero) Area Jember sebagai Badan Usaha Milik Negara yang ditugaskan oleh pemerintah untuk mengelola ketanagalistrikan berperan penting dalam menjaga ketersediaan pasokan dan pendistribusian tenaga listrik serta pelayanan produknya terhadap masyarakat Kabupaten Jember. Terkait dengan hal tersebut, terdapat dua indikator untuk mengukur kinerja PLN dalam menangani masalah keandalan pasokan dan pendistribusian tenaga listrik kepada pelanggan, yaitu SAIDI (System Average Interruption Duration Index) dan SAIFI (System Interruption Frequency Index).

SAIDI adalah jumlah lama padam yang dirasakan rata-rata per pelanggan per tahun dan SAIFI adalah jumlah kali padam yang dirasakan rata-rata per pelanggan per tahun. Buruknya penanganan terhadap kinerja dari SAIDI dan SAIFI dapat berpengaruh terhadap kepuasan pelanggan yang berujung pada meningkatnya jumlah pengaduan, kerugian finansial berupa tuntutan ganti rugi, hilangnya Kwh jual, kerusakan aset dan sebagainya bagi pemasok listrik yang dalam hal ini adalah PT. PLN sendiri.

Salah satu cara untuk mencapai kinerja SAIDI dan SAIFI yang baik adalah dengan melakukan optimasi ketersediaan material yang digunakan yakni salah satunya transformator atau biasa disebut trafo. Demi terwujudnya komitmen PLN dalam menurunkan nilai angka SAIDI dan SAIFI secara berkesinambungan, diperlukan manajemen material transformator yang lebih baik, sehingga ketika dibutuhkan replacement, material transformator yang dibutuhkan tersedia.

Kebutuhan replacement yang tidak terprediksi, dapat disebabkan oleh banyak hal. Sebagai contoh, dapat dilihat pada kebutuhan replacement transformator. Berdasarkan informasi yang diperoleh dari pihak perusahaan, replacement transformator dilakukan akibat adanya kerusakan hubungan singkat jaringan, kegagalan proteksi, maupun bencana alam. 
Artificial Neural Network (ANN) adalah suatu model komputasi yang mencoba untuk mensimulasikan jaringan syaraf biologis secara struktural dan/atau fungsional. ANN mengandung unit komputasi sederhana disebut neuron yang saling terhubung satu sama lain. ANN mampu mengidentifikasi dan mempelajari korelasi antara dataset input dan kecocokan nilai target. ANN dapat digunakan untuk melakukan prediksi, klasifikasi, dan asosiasi data.

Ant Colony Optimization (ACO) adalah pendekatan metaheuristik dalam penyelesaian suatu masalah optimasi yang sulit. ACO sendiri terinspirasi dari perilaku semut untuk menemukan jalur terpendek antara dua tempat yakni sumber makanan dan sarang mereka yang memiliki jalur acak. Pada penelitian ini ACO digunakan saat ANN melakukan proses pembelajaran dengan cara menentukan nilai beban sesuai dengan model kerja feromon pada algoritma semut. Algoritma ACO yang digunakan dalam penelitian ini adalah Continuous ACO, karena proses pencarian bobot ANN akan menggunakan algoritma ACO dalam menemukan solusi ruang masalah yang bersifat berkelanjutan.

Pada penelitian sebelumnya algoritma ACO digunakan untuk melatih ANN melakukan prediksi nilai tukar rupiah dan dolar Amerika. Dalam penelitian lain digunakan untuk melakukan optimasi persediaan multiitem pada perusahaan retail. Pada penelitian ini akan melakukan optimasi terhadap persediaan trafo pada PT. PLN Area Jember agar dapat melakukan penanganan dengan tepat apabila terjadi gangguan listrik sehingga kinerja SAIDI dan SAIFI pada perusahaan tersebut dapat meningkat.

Berdasarkan penelitian di atas, dibutuhkan aplikasi berupa optimasi persediaan material transformator yang diharapkan dapat menjadi gambaran kepada perusahaan dalam menentukan jumlah material transformator yang harus disediakan pada wilayah pelayanan area jember pada tiap rayon di Kabupaten Jember.

\section{Research Method}

Penjelasan tahapan-tahapan yang dilalui pada tahap analisa kebutuhan data dan proses pengembangan sistem.

\subsection{Jenis Penelitian}

Jenis penelitian yang dilakukan adalah penelitian kualitatif dan kuantitatif. Penelitian kualitatif dalam penelitian ini dilakukan dengan cara melakukan wawancara kepada PT. PLN Area Jember selaku pengambil keputusan mengenai bagaimana tata kelola persediaan trafo dan kebutuhan tiap bulannya serta melakukan pengumpulan data history selama 5 tahun terakhir.

Sedangkan metode kuantitatif yang digunakan adalah pada tahap pengumpulan data dan analisis dalam bentuk angka serta penelitian ini juga mengkaji teori dan metode yang sudah ada sebelumnya.

\subsection{Tempat dan Waktu Penelitian}

Penelitian dilakukan di PT. PLN Area Jember yang beralamatkan Jl. Gajah Mada No.198, Kaliwates, Kec. Kaliwates, Kab. Jember, Jawa Timur. Waktu penelitian dilaksanakan selama 3 (tiga) bulan yaitu pada bulan Oktober 2016 sampai dengan Desember 2016. Tahap penelitian selanjutnya dilakukan di Kampus Program Studi Sistem Informasi Universitas Jember beralamatkan Jalan Kalimantan 37 Kab. Jember dengan waktu penelitian dilakukan pada bulan Januari 2016 hingga Januari 2017.

\subsection{Tahap Pengembangan Sistem}

Metode pengembangan yang digunakan adalah System Develpment Life Cycle (SDLC) dengan model waterfall. Model waterfall adalah model yang melakukan pendekatan secara sitematis dan urut mulai dari analisis, desain, coding, testing, dan pemeliharaan yang dapat dilihat pada gambar 3.2.

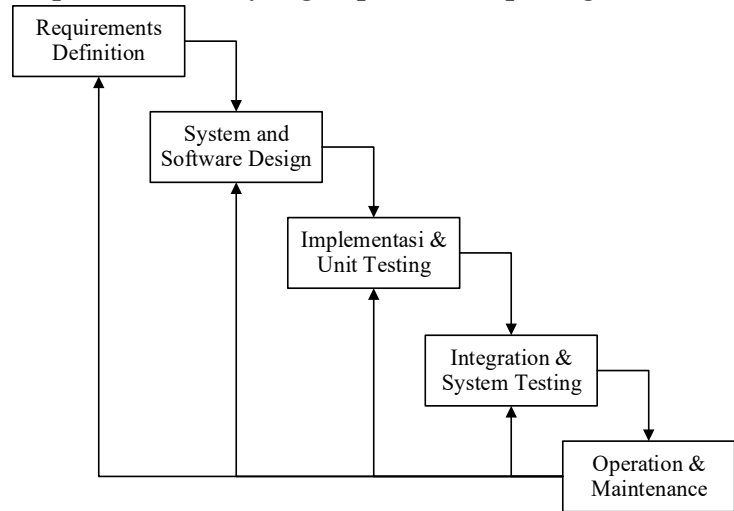

Gambar 3. 1 Model Waterfall (Pressman, 2001)

\section{Result and Analysis}

3.1 Perancangan Sistem 
Perancangan sistem ini dilakukan dengan menggunakan model waterfall meliputi analisis, desain, kode, pengujian dan pemeliharaan.

Analisis Kebutuhan

Pada analisis kebutuhan terdapat kebutuhan fungsional dan kebutuhan non fungsional. Berikut adalah kebutuhan fungsional sistem:

Sistem dapat mengelola (tambah, ubah, hapus) dataset persediaan trafo.

Sistem dapat menampilkan tabel persediaan trafo.

Sistem dapat mengelola (tambah, ubah, tampil) data kategori trafo.

Sistem dapat melakukan penghitungan metode ANN dengan ACO sebagai metode pembelajaran sesuai menggunakan dataset persediaan trafo sebagai sumber.

Sistem dapat menampilkan hasil prediksi persediaan trafo hasil perhitungan dari metode metode ANN dengan ACO sebagai metode pembelajaran.

Sistem mampu mengelola data user (create, view, edit, dan delete).

Kebutuhan non-fungsional sistem sebagai berikut :

Tampilan dan bahasa komunikasi sistem mudah dimengerti oleh pengguna untuk memberikan kenyamanan pemakaian dan memudahkan pengoperasian.

Sistem menggunakan username dan password untuk autentifikasi akses admin terhadap sistem.

\section{Desain Sistem}

Desain sistem terdiri dari Business Proces, Usecase Diagram, dan Entity Relationship Diagram

Business proses merupakan diagram yang menggambarkan data yang dibutuhkan oleh sistem. Business proses digambarkan pada Gambar Error! No text of specified style in document.. 1 Bussiness Prosess

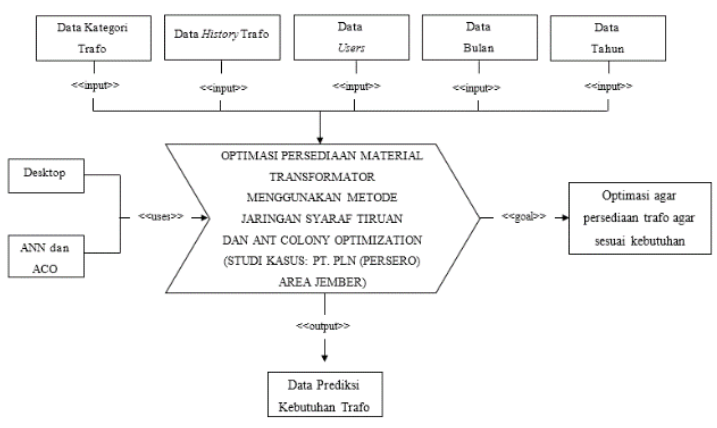

Gambar Error! No text of specified style in document..1 Bussiness Prosess

Usecase diagram merupakan diagram yang menjelaskan mengenai fitur yang terdapat pada sistem informasi peramalan kebutuhan air bersih serta aktor-aktor yang dapat mengaksesnya. Usecase sistem informasi peramalan kebutuhan air bersih dapat dilihat pada Gambar Error! No text of specified style in document..2 Usecase Diagram.

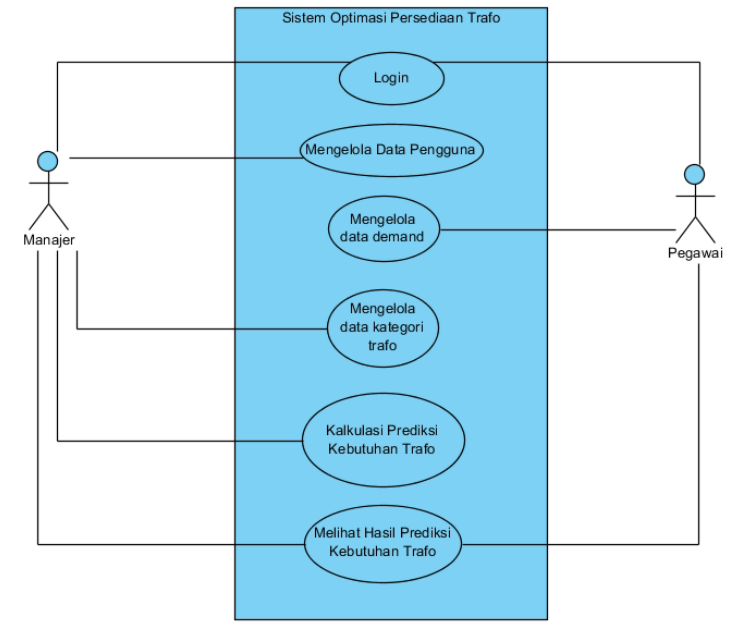

Gambar Error! No text of specified style in document..2 Usecase Diagram

Entity relationship diagram (ERD) merupakan diagram yang menggambarkan tipe objek mengenai manajemen data serta relasi antar objek data tersebut. ERD pada sistem informasi optimasi persediaan trafo dapat dilihat pada gambar 4.3 


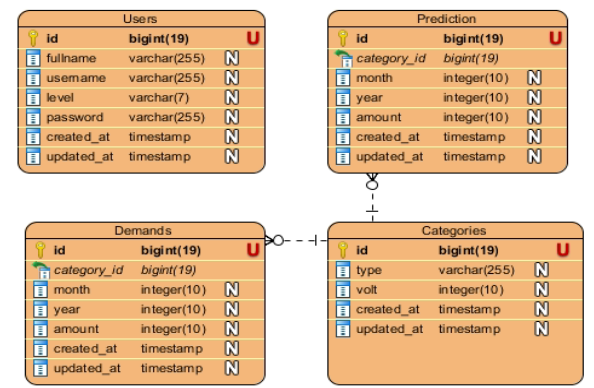

Gambar Error! No text of specified style in document..3 Entity Relationship Diagram

\subsection{Pembahasan}

Analisa dan pembahasan data demand trafo dalam sistem informasi optimasi persediaan material transformator menggunakan metode jaringan syaraf tiruan dan ant colony optimization.

Analisa Data Trafo

Data yang digunakan untuk kebutuhan trafo adalah data tahun 2012 hingga 2018. Kategori trafo yang dianalisa adalah trafo $50 \mathrm{MW}$.

\begin{tabular}{|c|c|c|c|c|c|c|c|}
\hline \multirow[t]{2}{*}{ Bulan } & \multicolumn{7}{|c|}{ Tahun } \\
\hline & 2012 & 2013 & 2014 & 2015 & 2016 & 2017 & 2018 \\
\hline 1 & 11 & 10 & 26 & 16 & 26 & 27 & 25 \\
\hline 2 & 19 & 24 & 10 & 14 & 15 & 12 & 11 \\
\hline 3 & 18 & 20 & 30 & 13 & 21 & 29 & 26 \\
\hline 4 & 17 & 23 & 28 & 27 & 11 & 17 & 10 \\
\hline 5 & 28 & 29 & 11 & 24 & 16 & 16 & 17 \\
\hline 6 & 14 & 30 & 22 & 23 & 22 & 22 & 12 \\
\hline 7 & 12 & 27 & 21 & 24 & 30 & 14 & 27 \\
\hline 8 & 25 & 26 & 17 & 14 & 24 & 13 & 19 \\
\hline 9 & 22 & 16 & 19 & 13 & 18 & 30 & 15 \\
\hline 10 & 21 & 29 & 15 & 28 & 23 & 24 & 18 \\
\hline 11 & 13 & 20 & 25 & 19 & 10 & 28 & 29 \\
\hline 12 & 15 & 12 & 18 & 20 & 25 & 20 & 23 \\
\hline
\end{tabular}

\section{Penerapan Metode pada Sistem}

Penerapan metode jaringan syaraf tiruan dan ant colony optimization dilakukan pada beberapa class yang terdapat pada package calculation. Sedangkan untuk mengelola dan menampilkan hasil dilakukan oleh class PredicionController dan ViewController. Pertama pengguna memilih kategori trafo yang akan dilakukan perhitungan prediksi. Lalu sistem akan melakukan perhitungan menggunakan class AnnACO sebagai class utama dalam mencari solusi.

AnnACO menggunakan fungsi getTimeSeries() pada class Demand untuk membaca data penggunaan trafo sejak tahun 2012 hingga 2018 dan menggunakan data tersebut sebagai data training dan data test untuk di proses oleh class DataProcessor. Data yang diproses adalah data berbentuk time series dimana data pertama adalah berupa input adalah bulan ke-1 hingga bulan ke-12 dan output adalah bulan ke-13, data ke-2 adalah input dari bulan ke-2 hingga bulan ke-13 dan output adalah bulan ke-14, dan seterusanya.

Oleh scaleDown() pada DataProcessor, data yang diperoleh dilakukan normalisasi. Selanjutnya data training diinisialisasikan pada class NeuralNetwork agar terbentuk dataset berupa model jaringan syaraf tiruan. AcoFramework menggunakan dataset pada NeuralNetwork untuk dilakukan pencarian solusi bobot terbaik berdasarkan nilai fitness. Pada saat nilai fitness memenuhi errorCriteria maka proses pencarian solusi bobot berhenti.

\section{Conclusion}

Kesimpulan dari penelitian yang telah dilakukan adalah:

1. Metode jaringan syaraf tiruan dan ant colony optimization sebagai metode pembelajaran dapat digunakan untuk menghitung prediksi jumlah penggunaan trafo pada bulan berikutnya.

2. Hasil prediksi jumlah penggunaan trafo pada bulan berikutnya dalam satu tahun dapat dijadikan patokan dalam menentukan kebutuhan.

3. Metode jaringan syaraf tiruan dan ant colony optimization sebagai metode pembelajaran dapat diterapkan dalam sistem berbasis Java guna mempermudah proses pengembangan sistem.

\section{References}

Hasibuan, M. S. (2007). Manajemen Sumber Daya Manusia Perusahaan. Bandung: PT. Bumi Aksa. Indonesia, D. P. (2008). Kamus Besar Bahasa Indonesia. Jakarta: Balai Pustaka. 
Nadjib, B., \& Dauzere, S. P. (2017). Production Planning: New Lot-Sizing Models and Algorithm. Editions Universitaires Europeennes.

Pang-Ning, T. (2006). Introduction to Dataming Pearson International Edition. Boston: Pearson Addison Wesley.

Pressman, R. S. (2001). Software Engineering: A Practitioner's Approach, Fifth Edition. New York: McGrawHill Higher Education (C2001.

SS, M., Ridwan, A., \& Juliani, W. (2015). Penentuan Kebijakan Persediaan Critical Spare Part Di Dipo Bandung Pt. Kereta Api Indonesia Dengan Pendekatan Metode Continuous Review System (S, S) Untuk Menentukan Penghematan Total Biaya Persediaan. Jurnal, 1-10. 